\title{
Exotización o neo-exotismo en el gran caribe hispano. Una mirada crítica al cine de ficción contemporáneo en la región
}

\author{
Exotizacion or neo-exoticism in the large Hispanic Caribbean. A critical \\ look at contemporary fiction cinema in the region
}

\author{
Carlos Alfonso López Lizarazu \\ Recibido: 27 de Marzo 2012. Aprobado: 25 de Abril de 2012
}

\begin{abstract}
Resumen
Establecemos el exotismo como noción y experiencia cultural afincada en el Gran Caribe. Particularmente, por asuntos metodológicos, nos ocupamos de algunos países del Caribe hispánico. Así, los años 80 y siguientes, muestran una industria cultural transnacional reacomodándose para mantener el control del negocio cinematográfico en la región, con, por ejemplo, la modernización de circuitos de exhibición theatrical en las urbes, garantizando el dominio tecnológico; la cooptación de talentos artísticos y temáticas locales para insertarlas en el mercado mundial, entre otras estrategias; pero lo más relevante para esta indagación la homogeneización de narrativas al estilo Hollywood.

El objeto de esta ponencia es cuestionar: ¿por qué, aún contemporáneamente, propios y extranjeros a la región, divulgan representaciones del Caribe como el territorio con "playas", "palmeras" y "mares deslumbrantes"? Sin duda, el exotismo es adoptado como estrategia para revitalizar la expresión cinematográfica y cautivar a las audiencias, pero, ciertamente, con el exotismo no se valora al Otro en su real significación, y al emplearse en el cine de hoy continúa relativizando la valía de los pueblos y las culturas del Caribe. Con esto el Gran Caribe Hispánico, es, pues, escenario de un evidente pero sutil debate entre un proceso de exotización que expresa, a través del cine, la realidad del Caribe contemporáneo, para distorsionarlo e invisibilizarlo; o existe, empero, una praxis neo-exótica que sólo afecta la forma cinematográfica y genera réditos económicos y turísticos en/para la región.
\end{abstract}

Palabras clave: Exotismo, Industria cultural, Caribe, Cine.

\begin{abstract}
We establish the exotic cultural experience as a notion and based in the Greater Caribbean. Particularly, due to methodological issues, we address some of the Hispanic Caribbean countries . Thus, following the 80's and show a transnational cultural industry reacomodándose to maintain control of the film business in the region, for example, modernization of theatrical exhibition circuits in cities, ensuring the technological domain, the cooptation of talents local art and to insert them into the global market, among other thematic strategies, but more relevant to this inquiry homogenization of Hollywood-style narrative.

The purpose of this paper is to question why, still contemporaneously, own and foreign to the region, as disclosed representations Caribbean territory with "beaches", "palm" and "dazzling seas"? No doubt, exoticism is adopted as a strategy for revitalizing cinematic expression and captivate audiences, but certainly with exoticism not valued the Other in its real significance, and
\end{abstract}

Poligramas 37, primer semestre 2013, ISSN 0120-4130. 
used in film today continues diminishing the worth of peoples and cultures of the Caribbean. With this the Wider Caribbean Spanish, then is an obvious scenario but subtle debate between a process exoticization expressing, through cinema, the reality of contemporary Caribbean, to distort and it invisible , or exists, however, a neo praxis - exotic that only affects the film shape and generate economic and tourism revenues in / for the region.

Keywords: Exoticism, cultural industry, Caribbean Cinema.

\section{El Caribe Hispánico y el cine exótico: un archipiélago fílmico singular.}

Vale la pena precisar que inspirados en cierta perspectiva fanoniana, esta ponencia busca superar la mirada local y trascender hacia un sentido suprarregional, pues, no hay país del Mar Caribe que no conozca del papel que juegan ciertos hegemonismos culturales para desplegar la idea de que esta región sólo encarna "el encanto exótico". De igual forma, precisar que en la actualidad la región no cuenta, en lo que se refiere al sentido justo del término, con una industria cinematográfica (GARCÍA BORRERO, 2006). Pues los procesos de producción, la frecuencia y el volumen nos impiden definirla de esta manera, por lo que, en esta ponencia apelamos más bien a nombrar toda la obra fílmica del Caribe como un archipiélago (BENÍTEZ ROJO, 1998:17). Con esto pueden encuadrar mejor en el tiempo y en el espacio las discontinuidades, las diversidades y la fragmentación, propios de la producción cinematográfica caribeñas. Así mismo y para cerrar esta suerte de delimitación, es imposible hablar de la experiencia cinematográfica del Caribe hispánico, sin considerar la praxis y la teoría cinematográfica surgidas en las demás regiones caribeñas (francófona, neerlandés, anglófona, portuguesa); de hecho aquí tenemos ya un problema cuando en la definición de Gran Caribe van incluidas la costa centroamericana y el norte de la suramericana como sustantivas de la caribeñidad; por tal motivo, esta ponencia no insiste en Centroamérica y Sudamérica separadas e inconexas del Caribe y recoge una mirada trans-areal (ETTE, 2011:11), para reflexionar sobre el cine en el ámbito hispánico de la región.

Luego de estas precisiones, partamos con un vistazo general a los años 30's al 50 del siglo XX. Allí se identifican apodos o nombres artísticos que llaman ampliamente la atención: 
"El ciclón del Caribe" que corresponde a María Antonieta Pons, "La Venus dorada" fue Ninón Sevilla; Rosa Carmina, conocida como "La mujer de fuego"; Meche Barba fue "La Venus Azteca". Estas mujeres y otras más, corresponden a un grupo de actrices que hicieron exitoso en la taquilla e instalaron en el imaginario social el llamado cine de rumberas (musical) y el cine de cabaret (policial), y fueron conocidas durante este tiempo como las Reinas del Trópico. De este período también es menester señalar, obligadamente, a Juan Orol (1897- 1988) y sus películas. Director, actor y productor español que se establece en Cuba y luego en México e impulsa este cine desde los años 30's hasta más o menos 1954, con filmes como Siboney (1938) y Sandra la mujer de fuego (1954), entre otros.

Con igual fuerza, indudablemente, en este período, aparece en la escena cinematográfica una de las figuras más emblemáticas de lo que el cine de ficción revela cuando emplea el exotismo: Carmen Miranda (1909-1955). Ella instaló en el imaginario social de la época un estereotipo de caribeñidad y latinoamericanismo asociado a la música y la danza, con sus 14 filmes para la Fox, MGM y Paramount. En estas películas interpretó personajes coronados con frutas, penachos multicolores y llamativos vestidos que estilizaron su figura. Sin duda, fue esta una acción interpretativa valiosa para el mundo artístico del momento, pero trascendió la mera estilización de la región, tal como señala PADRÓN (2011): "La estrella brasileña será uno de los elementos claves en ese estrechar de lazos entre "nuestras repúblicas" y el "buen" Vecino."

Ciertamente el llamado cine de rumberas y el cine de cabaret pudieron ser subgéneros que ofrecieron una cantera en la taquilla para las nacientes industrias nacionales y con esto el impulso a un fascinante starsystem propio. Pero, lo cierto es que su peso traspasó los límites de la oportunidad económica y generó una lectura codificada del Caribe en las pantallas de ese momento, como el lugar de la exuberancia y la diversión.

Ahora bien, en relación con nuestra pregunta del inicio, esta reflexión considera que es a partir de este momento cuando el cine exotiza de forma sistemática al Caribe en filmes de ficción realizados por autores latinoamericanos y no latinoamericanos. Debido a que este cine validó ideológicamente el exotismo al revivirlo mediante novedosos procesos de 
estilización visual y sonora. Del mismo modo, y no obstante esta carga evidente en el cine de rumberas y cine de cabaret, el período también ofrece otros elementos relevantes para insistir en este propósito exotizante y que estuvieron asociados a otros géneros como el melodrama y la comedia, y a otros artistas, por supuesto.

Precisamente, sobre este mismo período, GUBERN (1997) narra y reflexiona acerca de la presencia masiva del cine producido y co-producido entre España y, principalmente, México, Argentina y Cuba, en salas de su país y de Latinoamérica. Habla de una alianza que popularizó a directores y artistas como María Félix, Jorge Mistral, Lola Flores entre otros. Él se detiene en el tema idiomático, como vínculo y diferencia. Según Gubern, el castellano peninsular no fue del todo bien aceptado en la región y, a su vez, el público español no comprendía los modismos mexicanos, porque,

“... como principio general, el exotismo lingüístico ${ }^{48}$ sólo fue admitido por los públicos urbanos con un cierto nivel educativo, aunque a veces este exotismo jugó a favor de la popularidad de ciertas estrellas." 49

De esta afirmación llama la atención el hecho de que para Gubern, el exotismo esencialmente hace parte de la expresión formal y es un asunto legítimo y bien recibido pero por un público con buen nivel educativo y eminentemente urbano. De conformidad con esto, se puede inferir, entonces, que el exotismo es un problema que involucró en su momento (y aún) el concepto de clase social y/o sector social. Ya que, el "cierto nivel educativo" al que él se refiere es posible para quienes tienen acceso a la educación, a los medios de comunicación y a la formación artística. Por otro lado, resalta el contraste entre el sector rural y urbano de nuestros países, para colegir que el habitante de la ciudad cuenta con más oportunidades de "contacto" con el mundo y en ese relacionamiento el exotismo funge como estrategia para el conocimiento. Sin embargo, a renglón seguido, las preguntas obligadas se refieren a: ¿Qué tipo de conocimiento? ¿Con qué propósitos?

Sin embargo, con lo dicho atrás, es viable aquí generar una tensión para ganar en perspectiva, al contrastar esas visiones que naturalizan al exotismo con el pensamiento de, por ejemplo, CESAIRE (1955:25), cuando asocia la muerte de una sociedad para los que

\footnotetext{
${ }^{48}$ Resaltado nuestro.

${ }^{49}$ Ponencia de RomanGubern en el Congreso de la Lengua Zacatecas 1997.

Poligramas 37, primer semestre 2013, ISSN 0120-4130.
} 
aman al exotismo; o el de FANON (2007:178), cuando señala los trastornos y desviaciones que suscita el exotismo en la conformación de la conciencia y la cultura nacionales; y la de FERNÁNDEZ RETAMAR (2000:39) cuando se apoya en la noción “criollo exótico" de José Martí (1895), para establecer en el contexto de la guerra fría la presencia de intelectuales artificiales que se presentan con atuendo mestizo, pero aún representanta a la "América europea” de la que habló Martí?

Evidentemente, esta primera parte del siglo XX trae consigo la tensión entre cierta legitimidad para tomar el exotismo como estrategia artística y cultural, de sustrato primitivista o naíf, cultivado sin cortapisas por las metrópolis cinematográficas y avalado por sus agentes artísticos en la región, en debate con lonacional y lo extranjero, lo originalprimitivo y la copia-artificio. Tal como sucedió con los modernistas y surrealistas en el campo de la producción artística y literaria. No caben dudas que este período establece una resemantización del exotismo primitivista, en contradicción con una realidad económica, política y cultural que no puede divorciarse de los procesos y problemas sociales en la región.

\section{El cine contemporáneo: nueva exótica y exotización.}

A partir de los 80's, es evidente en y para la región articularse al nuevo escenario cultural marcado por nuevas condiciones políticas y económicas de orden mundial relacionadas con nuevas lógicas del consumo de masas, fortalecidas por la globalización. Las cuales buscan, por un lado, configurar un consumidor no solo de orden local sino internacional, y por el otro, el refinamiento de las hegemonías culturales.

Hay que señalar también que a pesar de la existencia de proyectos claramente políticocinematográficos en la región, como La Estética de la Violencia, el Cine Imperfecto y el Tercer Cine, con una clara perspectiva antiimperialista y anticolonial, que animaron el aglutinamiento de creadores y debates en torno a contenidos, estilos narrativos y crítica al consumo del cine para Latinoamérica, y, no obstante estas posturas que ponen en tesnsión el devenir de los cines nacionales, los años 80’s y siguientes muestran cómo la industria cultural transnacional se reacomodó para mantener el control del negocio en la región. Por ejemplo, con la modernización a ultranza de los circuitos de exhibición theatrical en las 
urbes; la cooptación de talentos artísticos y temáticas locales para insertarlas en el mercado mundial; el control monopólico de otras ventanas de exhibición como el home video y la televisión; y lo más serio, la homogeneización de narrativas al estilo Hollywood (SORLIN, 1996). Con lo cual se insiste en la dependencia cinematográfica como realidad de la region (PARANAGUÁ,2003). Dependencia que no procede exclusivamente del control de las materias primas y la teconología, sino, precisamente, dependientes por el suministro de obras. Dejando a la región el papel central de consumidores, tal como lo indica CORTÉS (2005) para toda Centroamerica pero que perfectamente se puede extrapolar al Caribe hispánico.

Evidentemente, estos reacomodos generan un cambio clave con dos direcciones: Por un lado en los temas a trabajar por los cines nacionales. En los cuales aparecen las problemáticas de género, étnica, ambiental, con las que la región dialoga en el concierto global. Y por el otro, el de los productores-directores externos a la región para crear películas asociadas a temas habituales como las luchas de liberación nacional, la censura política, el atraso y el progreso, con las que asumieron posturas en cierto sentido radicales y coherentes con las realidades representadas. No obstante esta disparidad en las direcciones señaladas, ciertamente, el modo para tratarlas fue unánime: el exotismo.

Esto trae consigo la aparición de filmes de consumo masivo provistos de un tratamiento dramatúrgico que aún recurre a la imagen exótica como telón de fondo, como estereotipo, como perspectiva, para abordar estas temáticas. Lo que indica, con HALL (2010), que asistimos a una de las expresiones de la llamada "nueva exótica"; manifestación que no aparece sólo en la gastronomía, música, plástica y publicidad, sino en el cine de ficción. Es decir, se trata de considerar la producción de películas locales, en co-producción, o de producción internacional, basadas en la diferencia cultural, con aire posmoderno, pero no para avalar y profundizar políticamente esta condición identitaria, sino porque ella permite proveer a los circuitos internacionales de consumo cultural de alto nivel adquisitivo con "nuevos" y "extraños" artefactos. En los cuales el espacio, el tiempo, las tramas, los personajes y los conflictos, que emanan del Caribe son etiquetados y catalogados en nuevos empaques que llevan la marca registrada de lo étnicamente diferenciado, pero que, en la 
práctica, logran el mismo efecto de antaño con los penachos y coronas de frutas de Carmen Miranda.

Con PADDINGTON (1992), estas "nuevas" imágenes van incrustadas en discursos estéticos que siguen ocultando los verdaderos problemas de la región:

"El uso del Caribe, en tanto que locación exótica, continúa hasta hoy mismo. Cuando el Caribe es identificado en uno de estos filmes, usualmente ocurre que se le emplea a modo de telón de fondo sobre el cual aparecen las estrellas, usualmente norteamericanas, lidiando con temas como el vudú, la piratería o el tráfico de drogas."

Lamentablemente, el cine ha sido y es instrumento importante en esta distorsión cultural,desorientado al mundo y también a los propios habitantes del Caribe.

Sin embargo, estas "nuevas" imágenes no corresponden exclusivamente a una producción europeo-norteamericana. Así mismo, y como lo hemos venido insinuando, pero aquí es el momento para precisarlo, el exotismo no es una praxis eurocéntrica exclusivamente (ROJAS-MIX, 1992), o dicho de otra forma, no es postura única del viajero extranjero y expresión eurocéntrica por excelencia, más bien es una condición etnocéntrica para asumir la superioridad sobre un otro que un nosotros ha definido como atrasado, bárbaro, primitivo, salvaje, extraño. En medio del debate sobre el cine y la identidad caribeños, se vislumbra que el cine local también puede ser portador de esta visión. Pues hoy los problemas del hambre, el daño ecológico, la corrupción, el patrimonio inmaterial, la inmigración, son los temas exóticos para el foráneo de nuestra región. Pero este es un foráneo instalado en sociedades con alto poder adquisitivo animado para consumir la nиеva exótica, la cual, instalada en la sociedad de consumo se erige como nuevo valor simbólico de estatus social y privilegiada forma de conocimiento del mundo. Lamentablemete, pues, aún, con ROCHA (1965),

“...los procesos de creación artística del mundo subdesarrollado sólo le interesan en cuanto satisfacen su nostalgia de primitivismo, un primitivismo híbrido, disfrazado de herencias

${ }^{50}$ PADDINGTON, B.Cine caribeño: imagen, identidad y producción.

Poligramas 37, primer semestre 2013, ISSN 0120-4130. 
del mundo civilizado mal entendidas porque son impuestas por el condicionamiento colonialista."

De modo similar estas realidades también pueden ser distorsionadas por los propios a la región. Al respecto se avisoran un par de justificaciones: por debilidad financiera para producir películas lo que obliga a hacer conseciones en el tratamiento; por asumir posturas advendizas frente a las relidades propias. PADDIGTON (1992) trae a colación el debate entre el crítico de cine Alain Menil y el director de cine guadalupano Cristian Lara: “... El Caribe es descrito en los filmes de Lara [ por ejemplo Adieu Foulard], a través de los ojos de alguien que es extranjero en su propio país, y resulta por lo tanto incapaz de reconocerse en otra etiqueta que no sea la del exotismo."52

Evidentemene, esta declaración no puede ser tomada como una rebatiña insulsa entre crítico de cine y autor cinematográfico, sino como expresión de un debate profundo y dinámico históricamente al que debe ponerse atención. Debido a que el caso de Lara no es el único, otros cinematografistas locales, en otras costas de la región, también usan al Caribe como telón de fondo para cautivar a un otro del primer mundo embelezado con la nueva exótica.

\section{Conclusión}

Finalmente, desde una perspectiva crítica, al auscultar el papel del cine de ficción y con destinación masiva en la región de lo que se está hablando no es de oportunidades de crecimiento y desarrollo vía la industria cultural, se habla de los significados que pueden tener para los ciudadanos del Caribe su codificación como exóticos y terminar "empacados" así en productos cinematográficos que, en un nuevo escenario cultural de alcances transnacionales, decididamente no proyectan sus realidades sino que contribuyen con la prolongación de procesos de invisibilización de sus identidades y de enajenación del derecho a sus valías culturales.

\section{Bibliografía}

Benitez, Rojo A. La isla que se repite. Barcelona. Ed. Casiopea. 1998.

${ }^{51}$ ROCHA, G. La estética del hambre.

${ }^{52}$ PADDINGTON, B. Op.cit. 
Cesaire, A. Discurso sobre el colonialismo. Recuperado el 17/06/2011 En:http://www.ceapedi.com.ar/imagenes/biblioteca/libros/173.pdf. p.25. 1955.

Cortés, M. Más allá de la pantalla rota. Cine y video en Centroamérica. Madrid. Fondo de Cultura Económica de España. p.533-547. 2005.

Ette, O., (eds.) Trans (it) Areas. Convivencias en Centroamerica y el Caribe. Berlín. Ed. Tranvía. 2011.

Fanon, F. Los condenados de la tierra. Recuperado E 14/11/2010. En:http://www.elortiba.org/ p. 178. 2007.

Fernández Retamar, R. Todo Calibán. Recuperado 18/12/2011. En: http://www.cubadebate.cu/wp-content/uploads/2009/05/todo-caliban-roberto-fernandezretamar.pdf. p. 39. 2000.

García borrero, J.A. Cuatro notas sobre el cine en el Caribe. Revista de cine cubano / On line / Octubre - Diciembre 2006. Recuperado el: 15/11/2011.En: http://www.cubacine.cult.cu/revistacinecubano/digital04/cap01.html. 2006.

Hall, S. (2010). Lo local y lo global. En: RESTREPO, E. (eds.). Sin garantías. Trayectorias y problemáticas en estudios culturales. Popayán. Envión Editores. p. 501-520. 2010.

Padrón, F. El "sistema de estrellas" latino en los años 30 y 40. Rostros en la muchedumbre. La Jiribilla - Revista de Cultura Cubana / Online/ 27 de AGOSTO al2 de Septiembre de 2011. Recuperado el 12/3/2012.

En:http://www.lajiribilla.co.cu/2011/n538_08/538_10.html

Paddington, B. Cine caribeño: imagen, identidad y producción. Recuperado el: 30/11/ 2010. En: http://www.eictv.co.cu/miradas. 2010. 